\title{
8 Lack of ordinary privileges in a gay man's life
}

\section{Navigating through privileged systems}

\author{
Yasin Koc
}

Feeling too close to an undesired possible identity is worse for well-being than feeling far from a desired possible identity.

Oyserman and James (2011, p. 140)

In this chapter, I will explore a number of disadvantages experienced through the lenses of sexual orientation. I call these disadvantages lack of ordinary privileges. The origin of the term 'ordinary privilege' dates back to McIntosh (2012) and has been adapted and elaborated by Greenwood et al. (2017). McIntosh defines ordinary privileges as an invisible package of unearned assets that comes with being a privileged White majority member. It sets the normative way of being for almost everyone based on the lives and experiences of the White majority. It is subtle, constant, and persistent, yet rarely recognised. As Greenwood and colleagues nicely quote from the song of Ani DiFranco: 'privilege is a headache that you do not know that you do not have' (Greenwood et al., 2017, p. 498). Beyond providing a continuous sense of belonging and validation for the White majority, ordinary privileges provide norms and standards according to which minority members feel obliged to establish and maintain their lives. However, these ordinary privileges are often not acknowledged or openly discussed. Therefore, not owning these ordinary privileges certainly has a negative impact on the identity and the wellbeing of the minorities. In this paper, through a life history approach, I want to explore a number of 'lack of ordinary privilege' examples related to sexual orientation, and how they affected my identity, sense of belonging, and wellbeing.

I grew up in Turkey in a big family with traditional cultural and religious values. For me, homosexuality was always incompatible with the two main value structures I was holding. In terms of religion, I thought homosexuality was condemned by God, and all homosexuals were sinners. In terms of cultural values, I knew that being a real man required one to be heterosexual. There were three stages one had to go through to achieve manhood in my culture: circumcision, being a soldier, and marrying a woman, all of which are celebrated with big parties. At the age of 19 , with a very late awakening of my sexual orientation, for the first time, I was confronted by myself on 
my own views. At first, it was a challenge for me to accept this new identity in my life. All I knew was that homosexuality was only about sex, homosexuals were all sinners, and the only visible homosexual men were effeminate men and caricaturised drag queens on TV. When I looked at myself in the mirror, I did not look like one of them. I also knew that most people in my society humiliated homosexuals. It would not be easy for me to accept this new identity. At first, I was in denial. I wanted to hide and change this identity. There was not possibly a way I could accept this. Later on, I did my research, went abroad for studies, met actual gay men in real life at university and elsewhere, and accepted that I was 'normal'.

Unfortunately, as a member of a stigmatised minority, I believe we do not grow up being exposed to any proper representation of our identities. Hence, it is often very hard to figure out where we stand in life. Am I working hard enough for my future? Am I a successful student? Am I a good person? Am I reliable? Am I attractive? Regardless of the reality, the answers to these questions always made me feel like I was a failure. And, now that I think about it, this was because I've always compared myself to the wrong people. Therefore, as soon as I accepted my new identity, two things happened. First, I made sense of a lot of my childhood miseries, and second, I rebuilt myself. Now, I will share several snapshots from my life, and attempt to deconstruct these memories with the knowledge and experience of my today self.

I was probably 15 years old. I visited a female friend for studies. Her father loved me. He always said he saw me like his son and he trusted me to protect his daughter. That day, we were in her bedroom studying, talking about her boyfriend, listening to some music, and then I left to go home. But there was a problem. A group of bullies who bung out in the streets were outside the apartment. With a stray dog. They were smoking, doing drugs, and talking and laughing loudly. They knew me. They always made fun of me and called me names: 'ibne, götveren' (meaning faggot and cock knocker) - some words you would know. They also said 'top, tekerlek' (meaning ball or tire) - which are our local slangs to state that one is round, not 'straight'. I waited in the building for nearly half an hour, but I had to go home, so I left the building. The fear was growing up from my feet to my head and giving me a rush. One of the bullies spotted me, they all started calling me names, and then one directed the dog against me. I started running, the dog chased after me, he attacked me, and I ran into a shop to save myself. I still have some physical but many more psychological bruises from that attack.

Until after I came out to myself, I did not understand what happened that day. Why did the bully boys hate me so much? What could have possibly motivated them to attack me? I went to the same school with some of them, so their psychological attack was constant and pervasive. But why would 


\section{Yasin Koc}

they make a dog attack me physically? For years, I did not know why. My parents and my teachers often told me 'I was special', but they always followed it saying, 'You are very smart'. Nobody was ready to even think about how else I could have been 'special'. But those boys hated me that day because I was not like them. I was not boyish or manly enough. I had female friends. In a traditional culture, I could visit those girls in their apartments for studies. Their fathers trusted me to look after them. I could even go to their bedroom and nobody needed to worry. Deep down, everyone knew why I was not a 'threat' to my female friends. But nobody acknowledged why - neither to me nor to themselves. Therefore, my real identity was hidden from me. Occasionally, it was even denied to me. Regardless, what I took from that day which still continues to prevail in my life is fear. When I see a group of lads, I feel the same fear growing up from my feet to my head. I get paralysed. I expect to be physically attacked and harmed because these things continue to happen all around the world. I have not been able to develop any better way of dealing with this threat. And I doubt I ever will do.

I could not talk about this experience to my family. I knew they would blame me for this. I can hear my siblings' voices: 'You should man up!' or 'Stop hanging out with girls!' or 'If you get beaten up and come back home, expect another round from me'. Imagine being bullied by your peers, feeling the constant fear of encountering them in wrong places, and not being able to ask for support from the people who love you. Because my fear of losing them was stronger than my fear of being bullied and attacked by stray dogs. That's what it means to grow up with an identity that is not recognised. There are no norms or no appropriate representations to learn from. The only ones available for me out there were incompatible with who I was. I am a member of a minority, and this is an example of how the lack of ordinary privileges makes one suffer in life. So, I had to find my own ways to construct my identity today.

It took me nearly five years to reach self-acceptance from first realisation. Looking back, I used these years to update and adjust my value systems. I stopped using the word 'homosexual' because who I was is not only sexuality or an orientation, but it is my gay identity. Yet my next fear was social rejection. Coming out to others is a process that cannot be undone; I did not want to risk losing everything (e.g., my family, my reputation, my dreams) by endorsing one identity of mine. At first, I spent a lot of time dealing with my own homophobia. The most efficient way was through contact. During my bachelor's education, I made gay friends at the university and spent time with them. This helped me reconsider others' position in my life. I decided to keep those who would see and accept me as who I was, and I would let the others go. This was happening because I had just learnt my life was not constrained by the traditions and rules of my culture, which prescribed heterosexuality and derided homosexuality (Eslen-Ziya and Koc, 2016). But there was more, because I believe if people are allowed to make 
their own choices about values, love, life, and work, there is a high possibility that they will select a psychologically rewarding match between their choices and their individual desires. But this was still not easy. How others perceived me set the boundaries of my identity for a long time:

One day I came out to a close friend, and she was not surprised. She was supportive and easily comfortable with my new identity. She asked me how the 'sex' worked. And I said it works as it would normally do. Clearly the question was one of the well-known: are you top or bottom? Then she said, 'I see no point in being a top. If you would be a top, you could as well be straight.' I fully disagreed with her, but I nodded in agreement.

Gay men often get asked inappropriate questions related to their sexuality. Some common ones are: 'Are you top or bottom? Do you use Grindr? Have you had sex with married straight men? Will you tell me if my boyfriend is gay? You use condoms, right?' After my self-acceptance and selective comeout to a small group of friends, I was immediately seen as an expert to answer these questions. For me, however, I was no more knowledgeable than anyone else. All I knew was 'If I would just be a top, I could as well be straight'. That's how the nature of my sexuality was defined for me for a long time: another person telling me how to be and who to be! I was confused though. Even though I felt and wanted things differently, I was not in a position to make sense of this confusion created by the wrong sources of information.

Although confusions can be resolved by seeking the right information, I realised those questions would never leave me alone. After coming out, I suddenly became the token gay man in a lot of straight people's lives, and I had to answer all their curious questions and represent the whole gay community. This is another manifestation of the lack of ordinary privileges: getting one's individual identity ignored and being asked to represent one's whole community at all times. How often do we ask heterosexual people how they have sex with their partners? Who is taking which role in bed? How often do we see heterosexual people's sexuality being underlined on the news in a completely unrelated news piece? The latter reminds me of a debate in Turkey in 2009. After a referee came out gay in Turkey, his contract was frozen by the referee association. A group of middle-aged straight men were discussing the fate of this referee in a sports TV programme, and one commentator said: 'I find it questionable to have gay referees. If they were to make a decision about a handsome footballer, how would we expect them to be fair? I think they will make decisions that will benefit the handsome, strong footballers'. He was wrong about his assumption that a gay referee would base his judgment on footballers' looks, but he was right that the judgment of the gay referee would be questioned based on his sexual orientation. And that was the case for me too. Hence, on top of fearing 
physical harm and social exclusion, I had the fear of being misunderstood in my actions. Would people judge me if a handsome student gets an A in my course, but the average-looking student gets a B? Would people believe that the grades are based on their work and not on their looks? Or how many straight professors experience the same fear? I reckon there will always be an asymmetry in our experiences as long as we, as gay men, are reduced to our sexual identities even while performing our professions, whereas heterosexuality remains to be an invisible factor in straight people's lives.

In an ideal world, I would like to only represent myself, but I have come to the conclusion that this is nearly impossible as long as I continue to interact with other people. My actions are perceived based on sexual orientation or on behalf of a whole community; moreover, their actions are also associated with me. And unfortunately, this is not simply because I come from a traditional background in a traditional society. My experiences were no less disappointing or less stigmatising when I moved to the UK. There were certain sets of behaviours, thoughts, and emotions I was allowed to express. Living accordingly, I was accepted and my identity was affirmed. In other cases, I was not good enough to be a gay man:

It was during the early stages of my PhD when I was planning to spend the weekend in my office to catch up with work. At the time, I was living with a gay guy. He asked whether I would join him to watch Eurovision or had I other party plans. When I said I was not sure if I could because I had work to do, he replied, 'I am not even sure whether you are really gay'.

My landlord struggled to categorise me into his mental box of what it means to be gay. I had to watch Eurovision. I did not know. My identity did not come with a user's manual. Later on, I learnt many other 'rules' that would make me gay. I had to go out every weekend. I had to love Madonna. I had to talk about my sex life openly. I had to be fashionable. I had to know who Marc Jacobs and Alexander McQueen were. I had to enjoy shopping. I had to help my friends shop. I had to look down on religion. I had to check out saunas or other cruising areas. I had to be a fan of RuPaul's 'Drag Race' or 'Queer Eye'. I had to be into hard-core partying and enjoy drugs. I had to hate kids and marriage. I had to drink excessively and die young. I had to find a boyfriend - but first, I had to sleep around.

My landlord was not alone. There were many gay or heterosexual people around who judged me based on the rules above. Often, I was called 'not gay enough'. Sometimes I finally looked or acted gay. I did not have a choice. This time, the emotion I felt was not fear, but it was frustration. Whenever I tried to have a conversation about any of these unspoken rules and personal choice, I was told that I would eventually learn. It is more reasonable to understand that the limits of my identity will be incorrectly drawn by a traditional society who is not familiar with my identity. However, it makes 
it difficult to see why a more open-minded society, or even other gay men, would deny me my own experiences of my identity and try to shape me into what they thought was a correct form of being gay. Perhaps it was to create norms and protect the gay identity, as it was known. They were not ready to accommodate my take on our identity. Because, in a way, they were superior to me when it comes to being gay. With their clearly condescending voice, I was told I would eventually learn because, for them, I had another barrier to understanding all of those: my non-White identity. My White saviours were there to show me the only and proper way to be gay. Coming from a traditional family and culture, I was there to learn and adapt, not find my own ways to express myself. I'd better comply and learn from them if I did not want to be ostracised again. And, that's what I did for a long time.

My intersectional identity of being a non-White gay man was not only a barrier for me to learning the proper ways of being gay: it was also a way others could discriminate against me and put the blame on me:

I was out with friends in a gay bar in Brighton. Late at night after a drag show, we were all dancing waiting for the pub to close so that we could all head to the next one. One handsome guy came closer and started dancing with me. It was a time when I had quite a long beard. He touched my beard and said, 'I really like your beard'. And I thanked him. He asked me where I was from, I replied, we danced more, and he continued, 'Is it Islamic?' I never heard of any beard being Islamic before. I asked back 'What?' and he asked 'Are you Muslim?' And I did not say no. 'Most people from Turkey are culturally Muslim'. And he continued, 'So do you support ISIS?' And this was completely out of nowhere. But for him, having a beard and being even culturally Muslim was enough to be an ISIS supporter. I was certain his behaviour was unacceptable, so I would not encourage him. I said 'This is not okay and I don't want to talk to you'. And his response was, 'Come ' $n$ ! Calm down! We're both gay. Nothing to hide here. Don't be too sensitive. You are not a lady!' Back and forth, this conversation did not go anywhere, until my White British friend came to my rescue and said 'Mate, my friend doesn't want to talk to you'. He left, and I was saved.

The aftertaste of this memory is still very bitter, but, for now, I only want to focus on my emotions and his assumptions at the time. Simply, I was angry. His conversation included sexism, racism, and homophobia altogether. By creating a common identity as gay for both of us, he thought it was okay to ask me such inappropriate questions, but it was my reaction that needed pruning. I was the one who had to calm down because I did not know the etiquette for conversation in a bar. At the end of the day, I was a 'foreigner' who needed to learn ways of being gay from him, as well as integrating into the British culture. He had the right to set the boundaries for my identity. I was used to experiencing or witnessing sexism, racism, and homophobia 
in my life. Hence, my anger did not directly derive from these, but entirely from his insistence on not leaving me alone despite my constant requests. He only respected the wish of my White saviour, and then he left me alone. This made me angry. I was nearly 30 years old, believing that I had rebuilt myself and was living in a free environment. Suddenly, I had to face the boundaries of my identity set by others again.

When I talk about this experience in class or workshops, I typically get one question all the time: do you think he left you alone just because your friend was White? To be honest, it does not matter. That's how it felt at the time, and that's how I still feel reflecting on that experience. And this is not about my experience only. This is an explanation based on identity theories and theories of oppression. On the one hand, I had our minority identity of being gay in common with him. Therefore, one might think he is not in a more privileged position. However, as identities intersect, his White identity gives him the legitimacy to even lecture me on my sexual identity. Therefore, when I asked him to leave me, the identity salient to him was his Whiteness. The way he addressed me, 'Come ' $n$ ! Calm down! We're both gay' was indeed a way to patronise me, instead of finding a common ground. Therefore, he only stopped when he was confronted by another person like him: a White gay man. Ultimately, I felt my agency was taken away from me, and my words had no meaning; so, I felt angry.

Finally, I want to share a recent unpleasant experience during a dinner with some colleagues. I categorise this experience as a moment of unnecessary sensitivity on my side, but I had the opportunity to understand the underlying reasons behind my reaction while writing this piece:

I was having dinner after work with a few colleagues. One of them also has stigmatised multiple identities like me. We do pick on each other a lot. And not all our jokes are always politically correct. One day, we were talking about his children. And he said 'You are not getting anywhere near my children'. They all laughed; I could not. The joke was appropriate, because he was referring to the fact that I often find children annoying, not to my sexuality. But I was suddenly extremely uncomfortable. I immediately went quiet, felt embarrassed, and almost scared. I almost felt like I'd been accused of child abuse, which was not in any other person's mind at the dinner table.

Members of the majority use a variety of strategies to stigmatise minorities. One example is the false association between paedophilia and homosexuality in the 70s. Although this is no longer recognised as a reasonable argument (at least in the Western world), it remains to be one of the driving forces for anti-gay attitudes among religious communities and countries across the world. And as it turns out, given the context, this might also be a trigger for gay men like me in the 2020s. Although I am entirely sure that my colleague did not refer to my sexuality during the conversation that 
night, I felt psychologically threatened once such an association was made in my own mind. Clearly, the heavy burden of the negative stereotypes is much stronger for minorities, and it implicitly persists even though those stereotypes are no longer readily available in the public domain. In the back of my mind, I feel like I am constantly being tested against my sexuality by everyone around me, and I have to be a good person to pass the test. Every interaction at work, with friends, or in shops is a test. The standards are higher for me as a minority member and I am constantly under the stress of my performance to be counted as a good person.

This reminds me of some fantastic research where the effect of meta-stereotypes in interactions are examined. Shelton and colleagues (2005) invited ethnic minority and White students into the lab for an experiment. Half of the ethnic minority students read an article about racial prejudice, and the other half read an article about prejudice directed against the elderly. Next, they had an interaction with White students and finally responded to some questions regarding the interaction. The idea was that the ethnic minority students reading about racial prejudice would be primed to expect prejudice towards themselves. The findings indicated that the ethnic minority students who read the racial prejudice article had more negative affect after the interaction, and they felt less authentic during the conversation. However, White participants who interacted with ethnic minority students reading about racial prejudice liked their partner more, enjoyed the interaction more, and reported less negative affect. This asymmetry in the experience clearly shows how we, as minorities, overcompensate in our daily interactions with the majority members which makes us liked by the majority more yet has consequences for us. Therefore, every interaction feels like I am constantly being tested against my sexuality by everyone around me, and I have to try to be a good person to pass the test.

\section{Reflections on my writing}

Moving forward, I want to reflect on my experiences and analyses above and situate them within the larger context of research in social psychology. McIntosh says privilege is the 'upside' of discrimination (2012, p. 203). Without examining how lack of privileges undermines belonging and selfesteem for the minority, our research into understanding the experiences of the minorities will remain incomplete. We know that the relationship between discrimination and well-being is well established. According to the meta-analyses by Schmitt and colleagues (2014), discrimination is linked to lower levels of self-esteem and life satisfaction - and higher levels of depression, anxiety, and psychological distress. However, these studies almost always focus on direct ways of discrimination that one can easily recognise: not recruiting someone with migration background into the workforce or treating someone badly due to their physical appearance, their age, gender, or race. However, the experiences I discussed are different than easily 
recognisable discrimination instances. They are disadvantages or lack of ordinary privileges, linked to a group membership, which are subtle and not widely accepted as discrimination. Therefore, coping with them is a lot more challenging because first we need to be able to recognise them.

If you witnessed someone being discriminated against next to you, perhaps you would intervene and try to help them. But how would you know about the psychological threat I experienced at the dinner with my colleague? That was a stereotype triggered in my mind out of nowhere. I do not suggest this is unique to me or to the gay community. Anything can be a trigger for someone that we may not be aware of. However, since negative stereotypes for stigmatised groups are more prevalent, I believe we experience this much more frequently. Besides, we are not equipped to deal with these challenges on our own while trying to figure our own identity processes. However, White privilege, male privilege, and heterosexual privilege are the established systems that not only communicate belonging to their members, but also provide tools for being successful and thriving in life. Stigmatised identities do not come with such established systems and tools. Minority members often deal with these challenges themselves.

I believe this is one of the reasons there is a higher prevalence of mental health problems among the gay community. According to Meyer's Minority Stress Model (2015), there is a unique stigma directed towards the LGBT community, and these unique stressors cause mental health issues. However, the model also suggests that, as a response to the stressors, minorities may develop resilience at the individual and community level. Individual-level coping involves building resilience through so-called individual resources and promotes success over adversities. However, this idea is based on meritocracy and ignores the structural inequalities by putting the responsibility on the individual. In reality, people do not have equal access to social, economic, and political structures, and these structural inequalities may limit their opportunities for resilience. Ultimately, minority members feel added stress to achieve resilience given their limited resources. In this way, society feels stripped off from their responsibilities, and we tend to blame the minority for their failure to build resilience. Contrarily, some minority members can also push the boundaries and become overachievers with significant costs to their mental health. I feel this has been one of the ways to cope with minority stress for me: I tried to excel in everything I do, and moreover, tried to do multiple things at a time. If I failed or disappointed someone for being gay, at least I could show that I had other achievements and I was worthy.

There is also community-level coping with discrimination which involves creating social support systems among the minority members and their allies and engaging in collective action to improve their status (Bourguignon et al., 2020; Koc and Vignoles, 2018). Such communities may contain role models to look up to and create norms and values about the identity. It then helps minority members have reference points for their identities and perhaps, 
ultimately, be the basis for compensating for the lack of ordinary privileges in our lives.

At the beginning, I mentioned that two things happened as soon as I accepted my new identity: first, I made sense of a lot of my childhood miseries, and second, I rebuilt myself. I gave some examples regarding several instances of thinking, making sense, and rebuilding. The good news is that it works. I have fewer fears now. I get frustrated or angry much less often about how others perceive me or treat me in relation to my sexual identity. Perhaps, this is because I am better equipped to challenge such negative attitudes and behaviours; perhaps, the world is becoming a better place treating me more like an equal (which is rather unlikely). Also, I have become an academic researching these topics as a form of political activism. This not only helped me learn more and build collective resilience, but also created a knowledge base for the community with academic and practical implications. However, I do not want these experiences to be perceived like a bildungsroman. One's own agency and hard work alone do not improve the situation. Regardless of all the efforts of adapting myself and finding a good fit between who I am and how I live, this progress is not linear. The reminder of an 'old-fashioned' stereotype can easily be a trigger of an identity threat. I am still exposed to questions regarding the intricate details of my bedroom life. I get judged in a conversation because I have not seen the latest (or any) episode of (Ru Paul's) 'Drag Race'. I am still afraid to disappoint my parents. Besides, such experiences can still trigger fear, anxiety, frustration, anger or shame about the situation or myself. Therefore, I continuously look back at the reservoir of tools I have, reinterpret my experience, seek the help and support of others, and find a way to cope with such threats to my identity. Finally, I am feeling closer to a desired possible identity than feeling too close to an undesired possible identity. Yet challenging lack of ordinary privileges is not about me, but it is about challenging the existing structures and improving the status of my community. Therefore, we still have a lot to do.

\section{References}

Bourguignon, D., Teixeira, C. P., Koc, Y., Outten, R., Faniko, K., and Schmitt, M., 2020. On the protective role of identification with a stigmatized identity: Promoting engagement and discouraging disengagement coping strategies. European Journal of Social Psychology, 50, 1125-1142.

Eslen-Ziya, H. and Koc, Y., 2016. Being a gay man in Turkey: Internalised sexual prejudice as a function of prevalent hegemonic masculinity perceptions. Culture, Health \& Sexuality, 18(7), pp.799-811.

Greenwood, R. M., Adshead, M. and Jay, S., 2017. Immigrant women's experiences of acculturative stress: Ordinary privileges, overt discrimination, and psychological well-being. Psychology of Women Quarterly, 41(4), pp.497-512.

Koc, Y. and Vignoles, V. L., 2018. Global identification helps increase identity integration among Turkish gay men. Psychology \& Sexuality, 9(4), pp.329-342. 


\section{Yasin Koc}

McIntosh, P., 2012. Reflections and future directions for privilege studies. Journal of Social Issues, 68(1), pp.194-206.

Meyer, I. H., 2015. Resilience in the study of minority stress and health of sexual and gender minorities. Psychology of Sexual Orientation and Gender Diversity, 2(3), pp.209-213.

Oyserman, D. and James, L., 2011. Possible identities. In Schwartz, S. J., Luyckx, K., and Vignoles, V. L. (Eds.) Handbook of identity theory and research (pp. 117-145). Springer, New York.

Schmitt, M. T., Branscombe, N. R., Postmes, T. and Garcia, A., 2014. The consequences of perceived discrimination for psychological well-being: A metaanalytic review. Psychological bulletin, 140(4), p.921.

Shelton, J. N., Richeson, J. A. and Salvatore, J., 2005. Expecting to be the target of prejudice: Implications for interethnic interactions. Personality and Social Psychology Bulletin, 31(9), pp.1189-1202. 